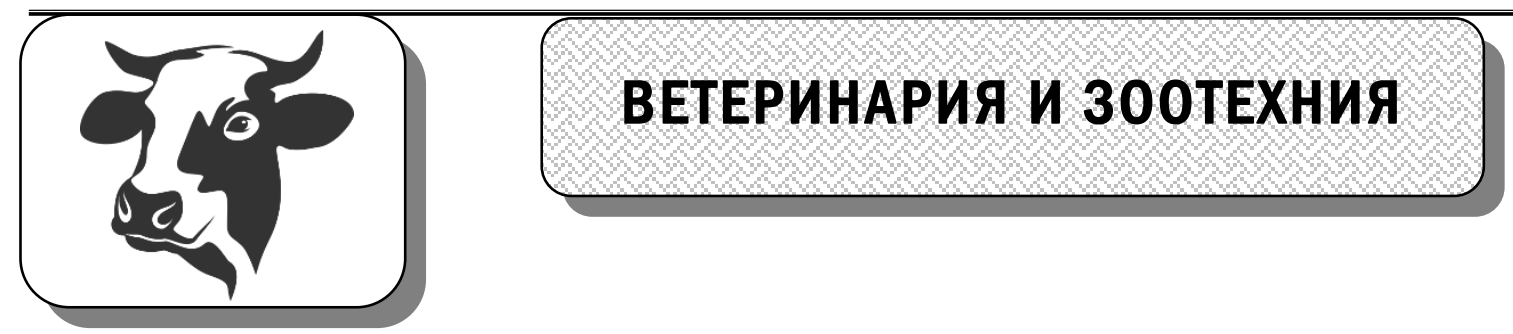

УДК 636.087.7: 636.51: 636.612.1

DOI: 10.36718/1819-4036-2019-12-69-76

Л.Е. Тюрина, Н.А. Табаков, Т.Ф. Лефрлер,

Е.Г. Турицына, Л.А. Военбендер

\title{
МОРФОБИОХИМИЧЕСКИЕ ПОКАЗАТЕЛИ КРОВИ ЦЫПЛЯТ-БРОЙЛЕРОВ И КУР-НЕСУШЕК ПРИ ИСПОЛЬЗОВАНИИ МЕСТНЫХ МИНЕРАЛЬНЫХ ИСТОЧНИКОВ
}

\author{
L.E. Tyurina, N.A. Tabakov, T.F. Lefler, \\ E.G. Turitsyna, L.A. Voenbender
}

\section{MORPHOBIOCHEMICAL INDICATORS OF THE BLOOD OF CHICKENS-BROILERS AND LAYING HENS UNDER USING LOCAL MINERAL SOURCES}

Тюрина Л.Е. - канд. С.-х. наук, доц. каф. зоотехнии и технологии переработки продуктов животноводства Красноярского государственного аграрного университета, г. Красноярск.

E-mail: Lilija-tjurina@yandex.ru

Табаков Н.А. - д-р с.-х. наук, проф. зоотехнии и технологии переработки продуктов животноводства Красноярского государственного аграрного университета, г. Красноярск. E-mail: zoofak@kgau.ru

Лефллер T.Ф. - д-р с.-х. наук, проф., зав. каф. зоотехнии и технологии переработки продуктов животноводства Красноярского государственного аграрного университета, г. Красноярск.

E-mail: leflertam@yandex.ru

Турицына Е.Г. - д-р ветеринар. наук, проф. каф. анатомии, патологической анатомии и хирургии Красноярского государственного аграрного университета, г. Красноярск. E-mail: turitcyna@mail.ru Военбендер Л.А. - канд. С.-х. наук, доц. каф. зоотехнии и технологии переработки продуктов животноводства Красноярского государственного аграрного университета, г. Красноярск.

E-mail: zoofak@kgau.ru

В статье представлены результаты исследования изменений биохимических и гематологических показателей крови иыплят-бройлеров кросса «Росс 308» и кур-несушек кросса «Родонит-2» при внесении в рацион минеральных добавок на основе отходов промышленных производств. Исследования проведены в период 20172018 г2. на базе ОАО ГПКЗ «Шушенская птице-
Tyurina L.E. - Cand. Agr. Sci., Assoc. Prof., Chair of Animal Breeding and Technology of Livestock Products Processing, Krasnoyarsk State Agrarian University, Krasnoyarsk.

E-mail: Lilija-tjurina@yandex.ru

Tabakov N.A. - Dr. Agr. Sci., Prof., Chair of Animal Breeding and Technology of Livestock Products Processing, Krasnoyarsk State Agrarian University, Krasnoyarsk. E-mail: zoofak@kgau.ru

Lefler T.F. - Dr. Agr. Sci, Prof., Head, Chair of Animal Breeding and Technology of Livestock Products Processing, Krasnoyarsk State Agrarian University, Krasnoyarsk.

E-mail: leflertam@yandex.ru

Turitsyna E.G. - Dr. Veterinary Sci., Prof., Chair of Anatomy, Pathological Anatomy and Surgery, Krasnoyarsk State Agrarian University, Krasnoyarsk.

E-mail: turitcyna@mail.ru

Voenbender L.A. - Cand. Agr. Sci., Assoc. Prof., Chair of Animal Breeding and Technology of Livestock Products Processing, Krasnoyarsk State Agrarian University, Krasnoyarsk.

E-mail: zoofak@kgau.ru

фрабрика» Шушенского района, ООО «ЕнисейАгроСоюз» Сухобузимского района Красноярского края и зоофермы Института прикладной биотехнологии и ветеринарной медицины ФГБОУ ВО «Красноярский государственный аграрный университет» (Красноярский ГАУ). Цель исследований - обоснование использования минеральных источников Красноярского края в составе 
комбикормов для птицы. Установлено, что минеральнье смеси на основе белитового шлама и минеральньх солей в рационе птицы повышают содержание эритроцитов в крови кур-несушек опытной группы более чем на 8 \% по сравнению с контрольной $(P \geq 0,999)$. Скармливание различных дозировок минеральных смесей улучшает фризиологическое состояние и обменные процессы в организме иыплят-бройлеров, о чем свидетельствуют биохимические и гематологические показатели опытной птицы. Содержание эритроцитов в обеих опьтных группах находилось в пределах физиологической нормы и превышало контрольные показатели на 10,3 и $17,4 \%$ ( $P \geq 0,99)$. Общее содержание лейкоцитов у птицы первой и второй опытных групп также находилось в пределах фризиологической нормы и было ниже контрольных величин соответственно на 44,6 и 40,2 \% ( $P \geq 0,999)$. Кроме этого, использование белитового шлама и окисленного бурого угля является одним из перспективньх направлений безотходной технологии переработки и добьчи глинозема и бурого угля на территории Красноярского края.

Ключевые слова: цыплята-бройлеры, минеральные добавки, белитовый шлам, вермикулит, торф, окисленный бурый уголь.

The study presents the results of the research of changes in biochemical and hematological parameters of the blood of broilers of the cross "Ross 308" and laying hens of the cross "Rodonite-2" when introducing into the diet of mineral supplements based on industrial waste. The research was carried out in the period 2017-2018, on the basis of JVC "Shushenskaya poultry farm" Shushensky district, LLC "YeniseiAgrosoyuz" Sukhobuzimsky district of Krasnoyarsk Region and zoofarm of the Institute of Applied Biotechnology and Veterinary Medicine FSBEI "Krasnoyarsk State Agrarian University" (Krasnoyarsk SAU). The purpose of the research was to substantiate the use of mineral springs of Krasnoyarsk Region in the composition of feed for the poultry. It was found out that mineral mixtures based on belite sludge and mineral salts in the poultry diet increased the content of erythrocytes in the blood of laying hens of experimental group by more than $8 \%$ compared to the control group ( $P \geq 0.999)$. Feeding different dosages of mineral mixtures improved physiological state and metabolic processes in the body of chickens-broilers, as evidenced by biochemical and hematological parameters of experimental poultry.
The content of erythrocytes in both experimental groups was within physiological norm and exceeded the control parameters by $10.3 \%$ and $17.4 \%$ $(P \geq 0.99)$. The total content of leukocytes in the birds of the first and second experimental groups was also within physiological norm and was respectively lower than the control values by $44.6 \%$ and $40.2 \%$ $(P \geq 0.999)$. In addition, the use of belite sludge and oxidized brown coal is one of promising areas of waste-free technology of processing and production of alumina and brown coal in Krasnoyarsk Region.

Keywords: broiler chickens, mineral additives, belite sludge, vermiculite, peat, oxidized brown coal.

Введение. Оценка рынка минеральных смесей в России показывает, что он только начинает формироваться. Рост производства комбикормов как объективной необходимости при производстве продукции животноводства и птицеводства имеет огромные резервы и высокую коммерческую привлекательность. Красноярский край на покупку премиксов и минеральных смесей ежегодно расходует не менее 200 млн рублей. Наш край в силу своего географического расположения и почвенно-климатических условий неоднороден. Исследования кормов края показали, что во многих хозяйствах районов края в кормах содержится недостаточное количество фосфора, меди, цинка, марганца, магния, железа, кобальта, йода, селена и других элементов, фризиологически необходимых для нормального роста и развития организма сельскохозяйственных животных. Корма различных почвенно-климатических зон края содержат неодинаковое количество минеральных веществ и неодинаково богаты микроэлементами [1].

Обеспеченность высококачественными полноценными, безопасными и более дешевыми комбикормами, а также соблюдение ветеринарно-санитарных требований во многом определяют уровень развития экономики птицеводства [2].

Поиск новых нетрадиционных источников, питательных и биологически активных веществ одно из важнейших направлений в научных разработках по кормлению птицы. В последние годы все большее внимание ученых и практиков привлекают проблемы использования для кормовых целей побочной продукции промышленных предприятий. В Сибири имеется большое количество металлургических заводов, побочные продукты данных предприятий богаты микроэлементами, что дает возможность включать их в рационы 
кормления сельскохозяйственных животных и птицы [3, 4].

По данным российских исследователей А.А. Арькова (2002), К.Я. Мотовилова (2008), А.Л. Сидоровой (2009), М.Г. Александровой (2010), А.В. Побединского (2011) и др. [5-9], разработка рецептуры комбикормов из местных дешевых и доступных традиционных и нетрадиционных кормовых средств является крайне актуальной. В качестве источников минеральных веществ, наряду с традиционными подкормками, в животноводстве стали применять природные минералы, такие как кудюриты, белитовый шлам, торф, сапропель, окисленный бурый уголь и пр. В связи с этим возникает необходимость в разработке и создании минеральных комплексов на основе минеральных источников Красноярского края при производстве комбикормов.

Цель исследований. Изучить морфобиохимические показатели крови цыплят-бройлеров и кур-несушек при включении в рацион минеральных смесей из местных источников.

Материал и методы исследований. На предварительном этапе эксперимента изучен химический состав, энергетическая питательность кормов, используемых в кормлении птицы, и разработан состав минеральных смесей из местных минеральных источников. Исследования проведены в три этапа. Целью первого этапа являлось изучение влияния минеральных смесей с включением в рацион отхода алюминиевого глиноземного производства на морфобиохимические показатели крови кур-несушек.

На втором этапе проведен научнохозяйственный опыт по сравнительному анализу различных минеральных смесей на основе местных минеральных сырьевых ресурсов. На третьем этапе - изучали влияние наиболее оптимальной дозировки минеральной смеси на морфобиохимические показатели крови цыплят-бройлеров.

Научно-производственные опыты на курахнесушках кросса «Родонит-2» со 105-дневного возраста проводились на ОАО ГПКЗ «Шушенская птицефабрика» в течение 150 дней. Птицу распределили в группы по принципу аналогов, по 100 голов в каждой.

Подопытные группы из цыплят-бройлеров кросса «Росс 308» формировались с десятидневного возраста, по 20 голов в каждой, по принципу аналогов (кросс, возраст, живая масса). Условия содержания, плотность посадки, фрронт кормления и поения, параметры микроклимата во всех группах были сфрормированы в соответствии с методическими рекомендациями для птиц по работе с кроссами «Росс 308» и «Родонит-2». Продолжительность опыта составила 32 дня.

В первом научно-хозяйственном опыте курынесушки контрольной группы получали полнорационный комбикорм (ПК), первая опытная группа ПК с содержанием 0,15 \% минеральной смеси № 1 (на основе белитового шлама с введением минеральных солей). Вторая опытная группа получала ПК с содержанием 0,5 \% минеральной смеси № 2.

На втором этапе сфрормировали пять групп из цыплят-бройлеров (контрольная и четыре опытных). Цыплята контрольной группы получали сбалансированный основной рацион (ОР), составленный по нормам ВНИТИП, а в рационах опытных групп проведена частичная или полная замена известняка и монокальцияфосфата на окисленный бурый уголь, белитовый шлам, вермикулит и торф, зерновая часть оставалась без изменений (табл. 1).

\section{Схема опыта (второй этап)}

Таблица 1

\begin{tabular}{|l|c|}
\hline \multicolumn{1}{|c|}{ Группа } & Особенности кормления \\
\hline Контрольная & Основной рацион (ОР) \\
\hline Опытная 1 & ОР+ окисленный бурый уголь $(0,8 \%)$ \\
\hline Опытная 2 & ОР+ торф $(0,35 \%)$, вермикулит $(0,5 \%)$, окисленный бурый уголь $(0,7 \%)$ \\
\hline Опытная 3 & ОР+ окисленный бурый уголь $(0,7 \%)$, белитовый шлам $(0,7 \%)$, вермикулит $(0,7 \%)$ \\
\hline Опытная 4 & ОР+ вермикулит $(0,4 \%)$, белитовый шлам $(0,4 \%)$, окисленный бурый уголь \\
$(0,4 \%)$, известняк $(0,9 \%)$
\end{tabular}

В первой опытной группе проведена замена 0,2 \% монокальциясоосфрата и 0,6 \% известняка на 0,8 \% окисленного бурого угля. Во второй опытной группе заменили 1,2 \% известняка и 0,35 \% монокальциясросфрата на 0,35 \% торфра, 0,5 \% вермикулита и 0,7 \% окисленного бурого угля. В третьей 
опытной группе вместо известняка и монокальцияфоссрата введены 0,7 \% окисленного бурого угля, 0,7\% белитового шлама и 0,7 \% вермикулита. В четвертую опытную группу внесены следующие компоненты: вермикулит $(0,4 \%)$, белитовый шлам $(0,4 \%)$, окисленный бурый уголь $(0,4 \%)$, известняк $(0,9 \%)$.
В третьем научно-хозяйственном опыте ссрормированы три группы цыплят-бройлеров (контрольная и две опытных). Контрольная группа получала основной рацион (табл. 2). Первая опытная группа получала в составе комбикорма известняк $(0,4 \%)$, окисленный бурый уголь $(0,4 \%)$, белитовый шлам $(0,4 \%)$, вермикулит $(0,4 \%)$, торфр $(0,3 \%)$.

Таблица 2

\section{Схема опыта (третий этап)}

\begin{tabular}{|l|c|}
\hline \multicolumn{1}{|c|}{ Группа } & Особенности кормления \\
\hline Контрольная & Основной рацион (ОР) \\
\hline Опытная 1 & ОР + известняк $(0,4 \%)$, окисленный бурый уголь $(0,4 \%)$, \\
белитовый шлам $(0,4 \%)$, вермикулит $(0,4 \%)$, торф $(0,3 \%)$
\end{tabular}

Во второй опытной группе были введены: монокальциясроссрат $(0,3 \%)$, известняк $(0,4 \%)$, окисленный бурый уголь $(0,4 \%)$, белитовый шлам $(0,4 \%)$, вермикулит $(0,4 \%)$.

Анализ крови птицы проведен по современным методикам исследований биохимических гематологических показателей [10].

Результаты и их обсуждение. В результате исследований установлено, что скармливание минеральных комплексов на основе отходов промышленных производств оказывает разнонаправленное влияние на биохимические и морфологические показатели крови опытной птицы (табл. 3).

Уровень гемоглобина во всех группах находился в пределах физиологической нормы, незначительно превышая контрольные показатели в пер- вой и второй опытных группах на 3,1 и 0,8 \% соответственно.

Введение минеральной смеси № 1 на основе белитового шлама положительно влияло на эритропоэз. Общее содержание эритроцитов в крови кур-несушек первой опытной группы более чем на $8 \%$ превысило контрольные данные $(P \geq 0,999)$. В то же время во второй опытной группе количество эритроцитов практически не отличалось от контроля.

Известно, что общий белок играет важную роль в поддержании осмотического давления крови, является важной буферной системой и участвует в транспортировке гормонов, питательных веществ и витаминов [10].

Таблица 3

Морфобиохимические показатели состава крови кур-несушек (первый этап), n=9

\begin{tabular}{|l|c|c|c|}
\hline \multirow{2}{*}{\multicolumn{1}{|c|}{ Показатель }} & \multicolumn{3}{|c|}{ Группа } \\
\cline { 2 - 4 } & Контрольная & Опытная 1 & Опытная 2 \\
\cline { 2 - 4 } & $\mathrm{M} \pm \mathrm{m}$ & $\mathrm{M} \pm \mathrm{m}$ & $\mathrm{M} \pm \mathrm{m}$ \\
\hline Гемоглобин, г/л & $90,55 \pm 1,40$ & $93,33 \pm 1,27$ & $91,25 \pm 1,27$ \\
\hline Эритроциты, ×1012/л & $8,10 \pm 0,01$ & $8,76 \pm 0,03^{* * *}$ & $7,90 \pm 0,13$ \\
\hline Общий белок, г/л & $54,07 \pm 0,64$ & $64,16 \pm 0,20^{* * *}$ & $52,33 \pm 0,54$ \\
\hline Альбумины, г/л & $22,48 \pm 0,25$ & $24,1 \pm 1,70$ & $24,0 \pm 1,40$ \\
\hline Альфа-глобулины, г/л & $10,8 \pm 2,11$ & $16,4 \pm 1,05^{*}$ & $11,2+0,80$ \\
\hline Бета-глобулины, г/л & $7,48 \pm 3,60$ & $9,56 \pm 1,50$ & $5,10 \pm 3,60$ \\
\hline Гамма-глобулины, г/л & $14,66 \pm 4,15$ & $15,24 \pm 0,90$ & $6,2 \pm 3,30$ \\
\hline
\end{tabular}

Примечание. Здесь и далее: * - $\mathrm{P} \geq 0,95 ;{ }^{* *}-\mathrm{P} \geq 0,99 ;{ }^{* * *} \mathrm{P} \geq 0,999$ по сравнению с контрольной группой. 
Нами установлено, что общее содержание белка в сыворотке крови кур первой опытной группы значительно превысило контрольные показатели. Уровень белка составил 64,16 $\pm 0,20$ г/л, что почти на $19 \%$ выше контроля $(P \geq 0,999)$. Достоверных отличий данного показателя у птицы второй опытной группы не обнаружено.

Содержание общего белка в сыворотке крови является интегральной величиной и складывается из альбуминов и глобулинов, которые, в свою очередь, делятся на три фрракции - альфа-, бетаи гамма-глобулины, несущие разную функциональную нагрузку в организме. Достоверно значимых различий между опытными и контрольными группами в содержании альбуминов не установлено (табл. 3).

Исследование белковых фрракций показало рост уровня альфра-глобулинов у птицы первой и

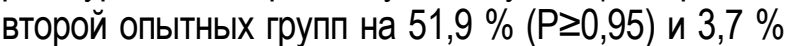
соответственно. А также увеличение содержания бета- $(27,8 \%)$ и гамма-глобулинов $(3,03 \%)$ у курнесушек первой опытной группы.

Таким образом, минеральная подкормка с включением 0,15 \% белитового шлама с добавлением минеральных солей стимулирует защитные силы организма, в результате чего повышается устойчивость кур-несушек к различным факторам внешней среды. Введение минеральной смеси № 1 на основе белитового шлама в состав кормосмеси кур-несушек оказывает положительное влияние на гематологические показатели птицы.
На втором этапе нами установлено, что максимальное содержание общего белка отмечено в первой опытной группе. Оно более чем на $6 \%$ превысило показатели контрольной группы $(P \geq 0,95)$. Минимальный уровень общего белка в сыворотке крови отмечен у птицы второй и третьей опытных групп, он на $15 \%$ ниже, чем в контроле, и почти на $20 \%$ меньше показателей первой и

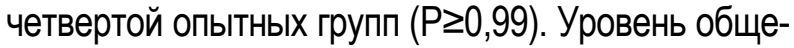
го белка в четвертой опытной группе на $5 \%$ отставал от контрольных величин (табл. 4).

Установлено, что введение минеральных смесей в рацион цыплят-бройлеров первой опытной группы не оказало негативного влияния на содержание альбумина в сыворотке крови, его уровень достоверно не отличался от показателей контрольной птицы. В то же время у цыплят второй, третьей и четвертой опытных групп содержание альбумина достоверно отставало от контрольных величин на 13,3 \%, 17,8 и 22,5 \% соответственно $(P \geq 0,95)$.

Одним из наиболее важных макроэлементов организма является кальций. Он понижает возбудимость нервной и мышечной ткани, является основой костной ткани организма, оказывает влияние на эфффективность гормонов, участвует в свертывании крови. В первой опытной группе содержание кальция превысило показатели контрольной птицы на 10,8 \%. Минимальный уровень общего кальция отмечен во второй и четвертой опытных группах. Он составил 1,97 $\pm 0,04$ и 2,14 $\pm 0,06$ ммоль/л соответственно, что достоверно ниже, чем в контроле $(\mathrm{P} \geq 0,99)$.

Таблица 4

\section{Биохимические показатели крови цыплят-бройлеров при введении в рацион минеральных смесей (второй этап), $\mathrm{n}=10$}

\begin{tabular}{|l|c|c|c|c|c|}
\hline \multirow{2}{*}{ Показатель } & \multicolumn{4}{|c|}{ Группа } \\
\cline { 2 - 6 } & Контрольная & Опытная 1 & Опытная 2 & Опытная 3 & Опытная 4 \\
\hline Кальций, ммоль/л & $2,73 \pm 0,06$ & $2,88 \pm 0,04$ & $1,97 \pm 0,04^{* *}$ & $2,44 \pm 0,11$ & $2,14 \pm 0,06^{* *}$ \\
\hline Альбумин, г/л & $20,86 \pm 0,06$ & $19,15 \pm 0,17$ & $18,08 \pm 0,13^{*}$ & $17,15 \pm 0,13^{*}$ & $16,16 \pm 0,09^{*}$ \\
\hline Фосфрор, ммоль/л & $2,10 \pm 0,14$ & $2,80 \pm 0,06^{*}$ & $2,34 \pm 0,11$ & $2,34 \pm 0,17$ & $2,41 \pm 0,09$ \\
\hline Общий белок, г/л & $35,5 \pm 0,22$ & $37,7 \pm 0,17^{*}$ & $30,2 \pm 0,12^{* *}$ & $30,0 \pm 0,19^{* *}$ & $33,5 \pm 0,11^{*}$ \\
\hline
\end{tabular}

Для полноценного обмена веществ в организме необходим фоссфор, обмен которого тесно связан с кальцием. Фосфрор является вторым после кальция компонентом костной ткани, участвует в поддержании осмотического давления крови, синтезе различных энергических соединений, является участником обмена нуклеиновых кислот, а также белков, жиров и углеводов. Введение минеральных смесей в рацион кормления цыплятбройлеров опытных групп способствовало росту содержания фоссфора в сыворотке крови. Количество неорганического фоссфора у птицы первой опытной группы превысило контрольные показатели более чем на 33 \% $(\mathrm{P} \geq 0,95)$, во второй и 
третьей группах - на 11,4 \%, а в четвертой группе - почти на $15 \%$. Независимо от состава минеральных смесей, введенных на первом этапе исследований в рацион экспериментальной птицы, достоверно значимых изменений в общем содержании эритроцитов не установлено (табл. 5). В то же время во всех опытных группах у цыплят- бройлеров отмечен рост общего содержания лейкоцитов, что свидетельствовало о развитии лейкоцитоза. Уровень лейкоцитов в крови значительно превысил контрольные показатели: в первой опытной группе - почти на $18 \%$, во второй - на 24, в третьей - на 44, в четвертой - на $20 \%$ $(P \geq 0,999)$.

Таблица 5

\section{Морфологические показатели крови цыплят-бройлеров при введении в рацион минеральных смесей (второй этап), $\mathrm{n}=10$}

\begin{tabular}{|l|c|c|c|}
\hline \multicolumn{1}{|c|}{ Группа } & Лейкоциты, $\times 10^{9} / л$ & Эритроциты, $\times 10^{12} / л$ & Гемоглобин, г/л \\
\hline Контрольная & $38,7 \pm 0,80$ & $4,65 \pm 0,10$ & $4,76 \pm 0,05$ \\
\hline Опытная 1 & $45,5 \pm 0,32^{* * *}$ & $4,59 \pm 0,14$ & $4,73 \pm 0,11$ \\
\hline Опытная 2 & $48,0 \pm 0,16^{* * *}$ & $5,19 \pm 2,83$ & $2,38 \pm 0,10^{* * *}$ \\
\hline Опытная 3 & $55,8 \pm 0,10^{* * *}$ & $3,19 \pm 0,07$ & $3,03 \pm 0,03^{* * *}$ \\
\hline Опытная 4 & $46,3 \pm 0,73$ & $4,42 \pm 0,02$ & $4,47 \pm 0,12$ \\
\hline
\end{tabular}

Проведенные гематологические исследования позволили выявить низкий уровень гемоглобина у всех опытных цыплят (см. табл. 5). При этом в первой группе содержание гемоглобина практически не отличалось от контрольных величин, а во второй и третьей группах было ниже в 2 и 1,6 раза соответственно ( $P \geq 0,999)$. Полученные данные свидетельствовали о возможности негативного влияния разработанных минеральных добавок на процессы кроветворения у цыплят-бройлеров. Это обусловило необходимость корректирования состава минеральных смесей и проведения третьего этапа научно-хозяйственного опыта.
В результате биохимических исследований крови установлено положительное влияние минеральных смесей, введенных в рацион цыплятбройлеров. Отмечено увеличение уровня общего белка в первой и второй опытных группах на $13 \%$ $(\mathrm{P} \geq 0,99)$ и $16,6 \%(\mathrm{P} \geq 0,95)$ соответственно по сравнению с контрольными показателями (табл. 6). При этом содержание альбумина сократилось на 6,5 \% в первой опытной группе и на


на уровне показателей фризиологической нормы.

Таблица
Биохимические показатели крови цыплят-бройлеров при введении в рацион минеральных смесей (третий этап), n=10

\begin{tabular}{|l|c|c|c|}
\hline \multirow{2}{*}{\multicolumn{1}{|c|}{ Показатель }} & \multicolumn{3}{|c|}{ Группа } \\
\cline { 2 - 4 } & Контрольная & Опытная 1 & Опытная 2 \\
\hline Кальций, ммоль/л & $2,76 \pm 0,06$ & $2,66 \pm 0,10$ & $2,28 \pm 0,05^{*}$ \\
\hline Альбумин, г/л & $17,29 \pm 0,08$ & $16,16 \pm 0,09^{* *}$ & $16,88 \pm 0,13^{*}$ \\
\hline Фосфрор, ммоль/л & $1,54 \pm 0,19$ & $2,31 \pm 0,10^{* *}$ & $1,53 \pm 0,11^{*}$ \\
\hline Общий белок, г/л & $27,53 \pm 0,27$ & $31,10 \pm 0,12^{* *}$ & $32,10 \pm 0,41^{*}$ \\
\hline
\end{tabular}

Содержание фосффора достигло оптимальной величины у птицы первой опытной группы и составило 2,31 $\pm 0,10$ ммоль/л, что в 1,5 раза превысило контрольные показатели $(P \geq 0,99)$. В то же время во второй опытной группе уровень фосффора не отличался от данных контрольной группы. Однако у птицы второй опытной группы отмечено достоверное сокращение уровня кальция в сыворотке крови на 17,4 \% по сравнению с контролем $(\mathrm{P} \geq 0,95)$.

Анализ гематологических показателей на третьем этапе эксперимента выявил отсутствие негативного влияния минеральных смесей, введенных в рацион цыплят-бройлеров, на общее содержание лейкоцитов, эритроцитов и гемоглобина (табл. 7). Содержание эритроцитов в 
обеих опытных группах находилось в пределах фризиологической нормы и превышало кон-



\section{Морфологические показатели крови цыплят-бройлеров при введении} в рацион минеральных смесей (третий этап), n=10

\begin{tabular}{|l|c|c|c|}
\hline \multicolumn{1}{|c|}{ Группа } & Лейкоциты, ×109/л & Эритроциты, $\times 10^{12 / Л}$ & Гемоглобин, г/л \\
\hline Контрольная & $57,26 \pm 0,22$ & $2,82 \pm 0,06$ & $7,88 \pm 0,06$ \\
\hline Опытная 1 & $31,75 \pm 0,34^{* * *}$ & $3,11 \pm 0,04^{* *}$ & $8,07 \pm 0,04^{*}$ \\
\hline Опытная 2 & $34,22 \pm 0,27^{* \star *}$ & $3,31 \pm 0,05^{* *}$ & $8,46 \pm 0,07^{*}$ \\
\hline
\end{tabular}

Общее содержание лейкоцитов у птицы первой и второй опытных групп также находилось в пределах физиологической нормы и было ниже контрольных величин соответственно на 44,6 и $40,2 \%$ ( $P \geq 0,999)$. Кроме того, установлено достоверное превышение уровня гемоглобина у опытных цыплят по сравнению с контрольными показателями.

\section{Выводы}

1. Окисленный бурый уголь, белитовый шлам, вермикулит, торф в кормлении цыплятбройлеров улучшают физиологическое состояние и обменные процессы в организме, о чем свидетельствуют морфобиохимические показатели крови опытной птицы.

2. Использование белитового шлама и окисленного бурого угля является одним из перспективных направлений безотходной технологии переработки и добычи глинозема и бурого угля на территории Красноярского края.

\section{Литература}

1. Табаков Н.А., Танделов Ю.П. Справочник зоотехника по организации рационального кормления сельскохозяйственных животных. - Красноярск, 1987. - С. 25-30.

2. Дмитриева M.E. Современные подходы к решению актуальных ветеринарных проблем в промышленном птицеводстве // Эффрективное животноводство. - 2016. - № 2. C. 9-11.

3. Кормовые добавки: справочник / А.М. Венедиктов, Г.А Дуборезова, Г.А. Симонов [и др.]. - М.: Колос, 1998. - 124 с.

4. Козлова Л.Г. Физиологическое обоснование применения вермикулита в птицеводстве: ав- тореф. дис. ... канд. биол. наук. - Троицк, 2002.

5. Патент RU 2213488C1. Кормовая минеральная добавка для птицы / Арьков А.А. - Волгоград, 2002. -3 c.

6. Мотовилов К.Я. Минеральные добавки, используемые в животноводстве // Кормление сельскохозяйственных животных и кормопроизводство. - 2008. - № 11. - С. 60-66.

7. Сидорова А.Л. Активированные цеолиты в рационах телят // Зоотехния. - 2009. - № 4. C.11-13.

8. Александрова М.Г., Табаков Н.А., Тюрина Л.Е. Влияние скармливания минеральной смеси на основе белитового шлама на физиологическое состояние дойных коров // Кормление сельскохозяйственных животных и кормопроизводство. - 2010. - № 4. - С. 12-15.

9. Побединский А.В. Эфрфективность использования вспученного вермикулита в кормлении сухостойных коров: автореф. дис. ... канд. с.-х. наук. - Красноярск, 2011. - 16 с.

10. Современные методы исследований биохимических показателей крови: учеб.-метод. пособие / А.И. Афранасьева, В.А. Сарычев, Е.Н. Пшеничникова [и др.]. - Барнаул: АлтайСКий ГАУ, 2018. - 274 с.

\section{Literatura}

1. Tabakov N.A., Tandelov Ju.P. Spravochnik zootehnika po organizacii racional'nogo kormlenija sel'skohozjajstvennyh zhivotnyh. Krasnojarsk, 1987. - S. 25-30.

2. Dmitrieva M.E. Sovremennye podhody $\mathrm{k}$ resheniju aktual'nyh veterinarnyh problem $v$ 
promyshlennom pticevodstve // Jeffektivnoe zhivotnovodstvo. - 2016. - № 2. - S. 9-11.

3. Kormovye dobavki: spravochnik / A.M. Venediktov, G.A Duborezova, G.A. Simonov [i dr.]. - M.: Kolos, 1998. - 124 s.

4. Kozlova L.G. Fiziologicheskoe obosnovanie primenenija vermikulita v pticevodstve: avtoref. dis. ... kand. biol. nauk. - Troick, 2002.

5. Patent RU 2213488S1. Kormovaja mineral'naja dobavka dlja pticy / Ar'kov A.A. Volgograd, 2002. - $3 \mathrm{~s}$.

6. Motovilov K.Ja. Mineral'nye dobavki, ispol'zuemye $\mathrm{v}$ zhivotnovodstve // Kormlenie sel'skohozjajstvennyh zhivotnyh i kormoproizvodstvo. - 2008. - № 11. - S. 60-66.

7. Sidorova A.L. Aktivirovannye ceolity V racionah teljat // Zootehnija. - 2009. - № 4. S.11-13.
8. Aleksandrova M.G., Tabakov N.A., Tjurina L.E. Vlijanie skarmlivanija mineral'noj smesi na osnove belitovogo shlama na fiziologicheskoe sostojanie dojnyh korov // Kormlenie sel'skohozjajstvennyh zhivotnyh i kormoproizvodstvo. - 2010. - № 4. - S. 12-15.

9. Pobedinskij A.V. Jeffektivnost' ispol'zovanija vspuchennogo vermikulita $\mathrm{V}$ kormlenii suhostojnyh korov: avtoref. dis. ... kand. s.-h. nauk. - Krasnojarsk, 2011. - $16 \mathrm{~s}$.

10. Sovremennye metody issledovanij biohimicheskih pokazatelej krovi: ucheb.metod. posobie / A.I. Afanas'eva, V.A. Sarychev, E.N. Pshenichnikova [i dr.]. - Barnaul: Altajskij GAU, 2018. - 274 s. 